\title{
MAGNETOSPHERIC RESPONSE OF TWO TYPES IN PSc GEOMAGNETIC PULSATIONS TO INTERACTION WITH INTERPLANETARY SHOCK WAVES
}

\section{V.A. Parkhomov}

Baikal State University,

Irkutsk, Russia, pekines_41@mail.ru

N.L. Borodkova

Space Research Institute RAS,

Moscow,Russia,nlbor@mail.ru

\section{A.G. Yahnin}

Polar Geophysical Institute RAS,

Apatity,Russia,yahnin@pgia.ru

Tero Raita

Sodankylä Geophysics Observatory,

Sodankylä, Finland, tero.raita@sgo.fi @sgo.fi

B. Tsegmed

Institute of Astronomy and Geophysics AS Mongolia, Ulaanbaatar, Mongolia,tseg@iag.ac.mn

\author{
S.Yu. Khomutov \\ Institute of Cosmophysical Research and Radio Wave \\ Propagation FEB RAS, Paratunka, Kamchatka, Russia, \\ hom@ngs.ru \\ A.Yu. Pashinin \\ Institute of Solar-Terrestrial Physics SB RAS, \\ Irkutsk,Russia,pash@iszf.irk.ru \\ V.E. Chilikin \\ Baikal State University, \\ Irkutsk,Russia,drfreez@yandex.ru> \\ A.A. Mochalov \\ Polar Geophysical Institute RAS, \\ Apatity,Russia,mochalov@pgia.ru
}

\begin{abstract}
Using the June 22, 2015 event as an example, we present new data confirming the presence of a precursor of the sudden magnetic impulse caused by a powerful interplanetary shock wave (ISW). The precursor in the form of a train of oscillations (broadband pulse) with a falling frequency in the range $0.25 \div 11 \mathrm{~Hz}$ with a duration of $\sim 20 \mathrm{~s}$, which had a spectral resonance structure, was recorded globally by a network of induction magnetometers at 18:33:27 UT. No significant phase delays of the signals were detected in four frequency bands at widely spaced observatories. It is suggested that the impulse can be excited in the Earth -
\end{abstract}

ionosphere waveguide by a pulsed electric field which occurs in the ionosphere due to the short-term impact of ISW on the magnetosphere.

Keywords: sudden magnetic impulse, global precursor, broadband burst of geomagnetic pulsations, spectral resonance structure, Earth - ionosphere resonator, ionospheric Alfvén resonator.

\section{INTRODUCTION}

The impulse action of the interplanetary shock wave (ISW) on the magnetosphere occurs for a short time and causes a number of global disturbances. The most pronounced and well identifiable effects are positive and negative magnetic impulses, which are divided into sudden storm commencements (SSC ${ }^{*}$ ) and sudden impulses (SI*). The symbol * is used when a positive change of the geomagnetic field is preceded by a shortterm change of the geomagnetic field with the opposite sign - the preliminary reverse impulse (PRI). The results of the study of these phenomena for more than 100 years are summarized in the review by Curto et al. [2007]. The $H$-component rise time from the beginning of the SSC event to its maximum, determined from INTERMAGNET data, ranges from 2 to $10 \mathrm{~min}$ with an average of $4 \mathrm{~min}$. In geomagnetic pulsations, the response to sudden impulses are bursts of oscillations in a wide frequency range $0.0016-5 \mathrm{~Hz}$, (geomagnetic pulsations Psc1-5).

Induction magnetometers with high sensitivity and $100 \mathrm{~Hz}$ sampling rate installed in observatories allow us to find new features of sudden magnetic impulses. Parkhomov et al. [2014, 2017] have reported on short-term $(\leq 20 \mathrm{~s})$ precursors of SSC - impulsive bursts of geomagnetic pulsations in a frequency range $0.2-7 \mathrm{~Hz}$, which occur before sudden commencements of geo- magnetic storms with a sharp increase in the horizontal component $\Delta H$. The bursts were observed mainly for the northward vertical component of the interplanetary magnetic field (IMF). We designate IMF components using the solar-ecliptic coordinate system GSE.

Parkhomov et al. [2014] have studied characteristics of pulsation bursts, employing data from ground-based magnetometers and solar wind (SW) parameters. Parkhomov et al. [2017] in addition to ground-based data including magnetic field and riometer absorption observations utilized particle precipitation data from POES satellites. It has been shown that the onset of the magnetic storm on March 17, 2015 was preceded by the global generation of a train of oscillations with a duration of $\sim 4 \mathrm{~s}$. On the day side, this train was, in turn, preceded by energetic electron and proton precipitation, which might have been due to the development of cyclotron instability during compression of the magnetosphere.

A characteristic feature of the bursts of geomagnetic pulsations examined by Parkhomov et al. [2014; 2017] is a comb-shaped character of energy distribution in the oscillation spectrum. This distribution is usually called the spectral resonance structure (SRS) and is associated with the presence of the ionospheric Alfvén resonator (IAR) in the magnetosphere [Polyakov, Rapoport, 1981; Belyaev et al., 1989] or with interference of lightning discharge signals, which are direct and reflected from 
the upper ionosphere [Fedorov et al., 2014]. Features of the morphology and daily behavior of SRS at different latitudes have been examined in [Bösinger et al., 2002, 2004; Semenova, Yahnin, 2008; Yahnin et al., 2003].

The published results provide insufficient information about the nature of the burst of pulsations occurring before classic manifestations of sudden magnetic impulses. In this paper, we present new data obtained from the analysis of the phenomena accompanying a positive magnetic impulse with an amplitude of $\sim 110 \mathrm{nT}$. This impulse was the last and largest of those recorded on June 21, 2015 at 16:44 UT (1), June 22, 2015 at 05:44 UT (2) and at 18:33 UT (3) (Figure 1,2). These impulses were caused by the interaction of three ISW with the magnetosphere [http://umtof.umd.edu/pm/FIGS.HTML].

According to the data from the International Service on Rapid Magnetic Variations

[http://www.obsebre.es/en/rapid], all these impulses are classified as SSC. However, in [Gromova et al., 2016], the first two impulses have been assigned to the SI type; and the third, the most strong positive magnetic impulse ( $\triangle S Y M-H \sim 110 \mathrm{nT}$ ), to the SC type. To avoid doubt, we call all the three positive jumps of the geomagnetic field, which occurred after the interaction of the magnetosphere with three ISW, magnetic impulses, numbering them by the observation time (Figure 1,2). In the frequency range of geomagnetic pulsations, all the impulses were followed by Psc1-5 bursts. The burst of pulsations (precursor) of interest occurred during the last of the events, and it is the focus of attention here.

\section{DATA}

Properties of ISW and some features of the magnetospheric disturbance have been determined from the data acquired by WIND, THEMIS, ACE, SOHO, Cluster (C2, C1, C3, C4), SpR (Spectr-R), GOES-13 and GOES-15 (G13 and G15), and GTL (Geotail) satellites [https://cdaweb.sci.gsfc. nasa.gov/cdaweb/istp_public/, https://satdat.ngdc.noaa. gov/sem/goes/data/full].

The response in the geomagnetic field has been determined using data from global networks of fluxgate and induction magnetometers. Table 1 gives information about magnetic observatories whose data are used in this paper, lists types of magnetometers and sampling rates of records from each observatory. Figure 3 shows the geographical location of the observatories at the time of observation of magnetic impulses 1-3 caused by the interaction with three ISW.

\section{PARAMETERS OF JUNE 21, 2015 AND JUNE 22, 2015 ISW}

Variations in SW and IMF parameters ahead and behind the fronts of ISW considered are displayed in Figure 1. From top to bottom are indices of geomagnetic activity $S Y M-H$ and $A E$, densities, $V_{x}$ component of SW, dynamic pressure, IMF vertical component $B_{z}$ and modulus.

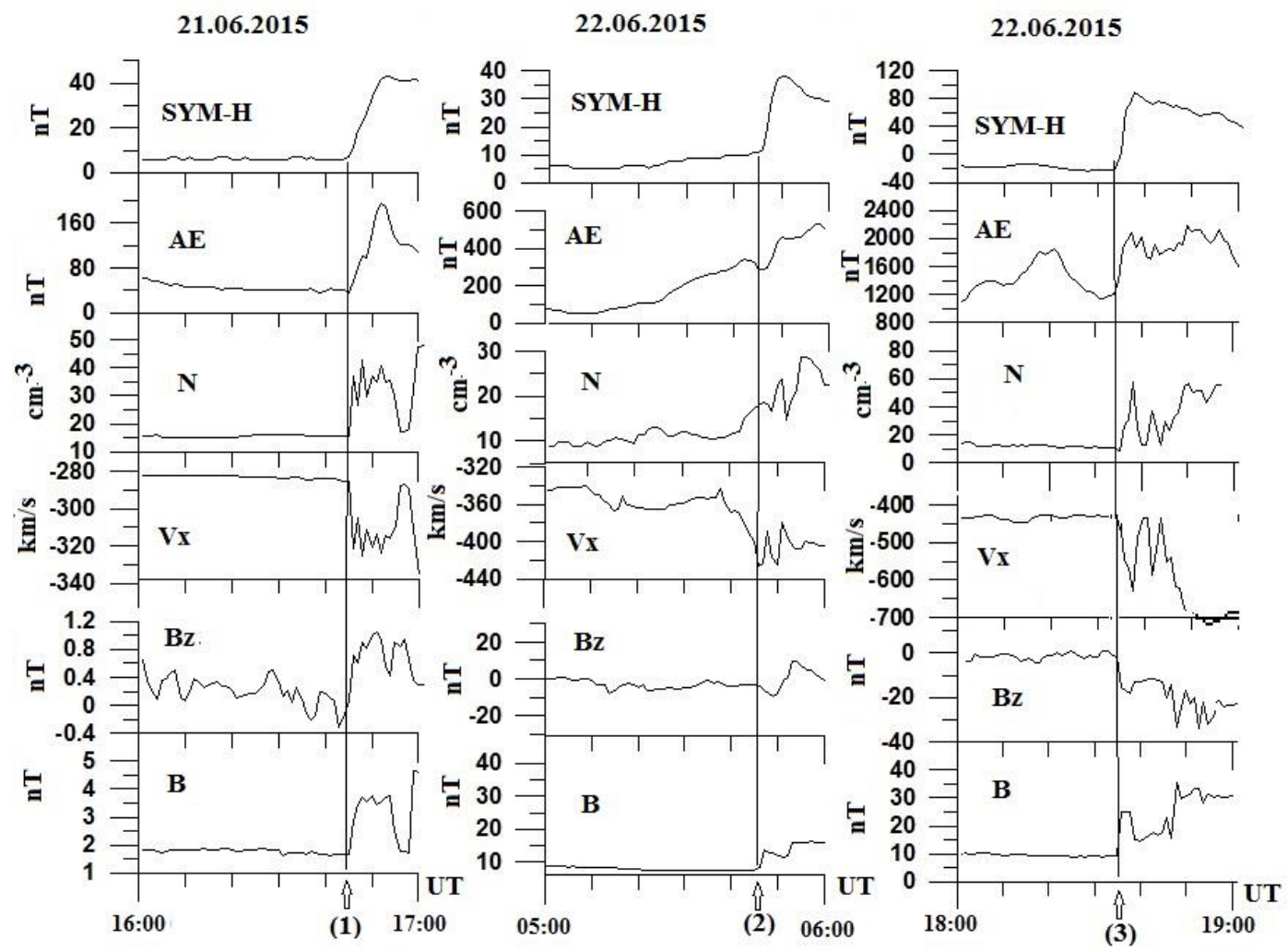

Figure 1. Variations in SW and IMF parameters at the fronts of three ISW and geomagnetic activity indices as derived from OMNI data [https://cdaweb.sci.gsfc.nasa.gov/cdaweb/istp_public/]. Vertical lines represent the times of sudden impulses: 16:44 UT on June 21, 2015 (1), 05:44 UT on June 22, 2015 (2), and 18:33 UT on June 22, 2015 (3) 


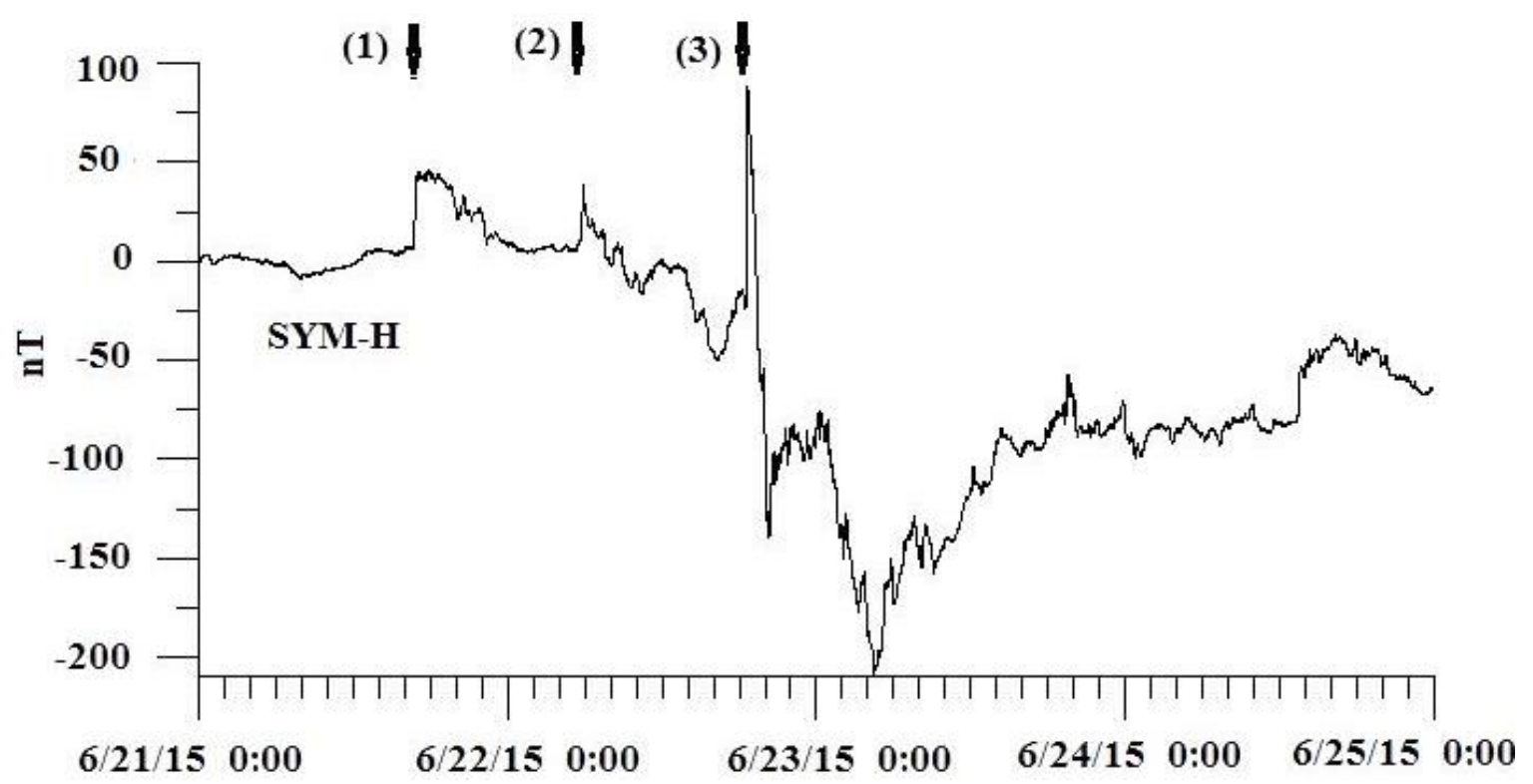

Figure 2. Magnetic storm caused by the arrival of three ISW. Numbers refer to sudden magnetic impulses
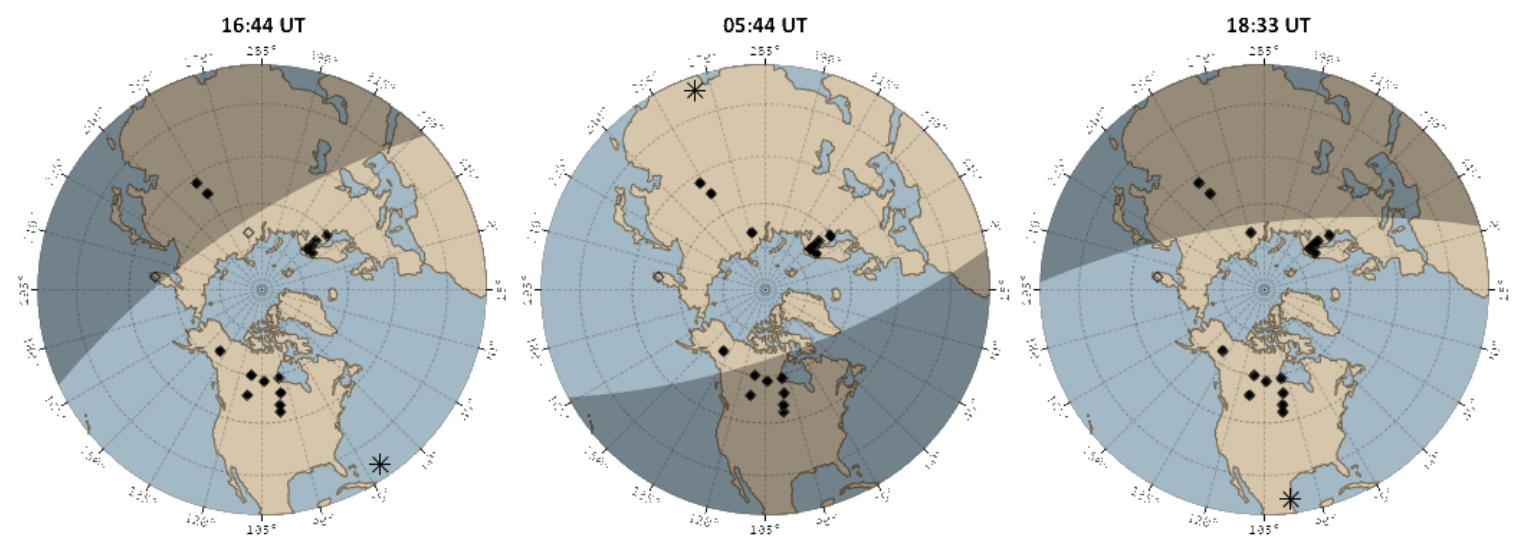

Figure 3. Geographical location of observatories at the times of observation of magnetic impulses $1-3$. The subsolar point is marked with an asterisk.

The disturbance onset time and the position of the WIND, Geotail, SpR, THEMIS, G-13, G-15, and RBSP (A, B) satellites in SW, transition layer, and inside the magnetosphere during recording of the third magnetic impulse on June 22, 2015 are shown in Figure 4.

Table 2 lists dates and times of ISW observations, wavefront normals determined by a particular geometrical method, ISW velocities; $\theta\left(B_{n}\right)$ is the angle between the wavefront normal and the magnetic field vector ahead the front. In brackets is the satellite from which magnetic field measurements have been taken. The subsequent columns present SW and IMF parameters ahead and behind the front of ISW and jumps of parameters.

\section{RESPONSE IN GEOMAGNETIC PULSATIONS TO THE INTERACTION BETWEEN \\ THE MAGNETOSPHERE AND ISW}

The impact of ISW on the magnetosphere excites geomagnetic pulsations in a wide frequency range; the pulsations are referred to as Psc1-5 [Saito, 1969]. They are a reflection of Alfvén and magnetosonic waves of various types, which are excited due to the interaction of the magnetosphere with ISW and its subsequent compression. Mechanisms of excitation of geomagnetic pulsations, caused by the magnetosphere-ISW interaction and SW pressure jumps, have been examined in numerous articles and reviews (e.g., monographs [Nishida, 1980; Leonovich, Mazur, 2016] which describe in detail the $0.1-0.0016 \mathrm{~Hz} \mathrm{LF}$ range of oscillation spectrum; [Olson, Lee, 1983]; the review [Kangas, et al., 1998] and the monograph [Guglielmi, 1979] which describe the mechanisms of generation of the $0.1-5 \mathrm{~Hz} \mathrm{HF}$ range of pulsation spectrum).

Figure 5 shows the dynamic spectra of Psc1-5 geomagnetic pulsations observed during the magnetic impulses produced by the three ISW. The spectra are calculated for the horizontal geomagnetic field component $H$, using the spectral-time analysis program (SWAN) [Levshin et al., 1968].

Let us examine features of the mode of geomagnetic pulsations. First of all, it is clear that all the three events are accompanied by the generation of the LF branch $(0.0016-0.05 \mathrm{~Hz})$ of oscillation spectrum. The smallest number of low-frequency spectral components was observed during the first event. The first two impulses 
generated by ISW at the fronts of which the dynamic pressure and velocity jumps were respectively $\Delta P_{1}=6.9$ $\mathrm{nPa}, V_{1 \text { isw }}=327 \mathrm{~km} / \mathrm{s}$ and $\Delta P_{2}=6.13 \mathrm{nPa}, V_{2 \text { isw }}=440$ $\mathrm{km} / \mathrm{s}$ were followed by well identifiable Psc1-5. In both the bursts, the Psc1 frequency was less than $1 \mathrm{~Hz}$. Furthermore, in the first case the magnetospheric compression caused an increase in the frequency of Pc1 pulsations, observed before the impulse from 0.4 to $0.8 \mathrm{~Hz}$, and an expansion of the Pc1 band [Olson, Lee, 1983; Kangas et al., 1998]. In the second case, the ISWmagnetosphere interaction generated $\mathrm{Pc} 1$ pulsations with an inclined leading edge of frequency rise from 0.4 to $0.8 \mathrm{~Hz}$. Properties of such oscillations in the Pc1 frequency range associated with sudden magnetic impulses and SSC were considered in detail in [Guglielmi, 1979; Safargaleev et al., 2002; Parkhomov et al., 2015]. In general, features of the mode of geomagnetic pulsations accompanying magnetic impulses 1 and 2 (Figure $5, a$ ) correspond to the known mechanisms of excitation of pulsations during sudden impulses and SSC [Saito,
1969, Nishida, 1980; Kangas et al., 1998].

The third ISW propagating at a velocity of $712 \mathrm{~km} / \mathrm{s}$, with high jumps of dynamic pressure $(\triangle P \sim 50 \mathrm{nPa})$ and other parameters SW and IMF at its front generated a positive magnetic impulse of high amplitude ( $\triangle S Y M$ $H=\sim 110 \mathrm{nT}$ ) (Figure 5, b). Before the interaction, as in cases of 1, 2, Pc1 pulsations were recorded with the mean frequency of $\sim 0.3 \mathrm{~Hz}$, but the interaction with ISW abruptly changed the mode of the pulsations occurring before the sudden magnetic impulse. The main feature of the interaction is the generation of a broadband burst in the HF spectrum range $0.5-11 \mathrm{~Hz}$. The burst is indicated by the horizontal arrow in Figure 5, $a$ (panel 3 ). Thus, the analysis of responses in geomagnetic pulsations to the ISW-magnetosphere interaction suggests that modes of Psc geomagnetic pulsations depend on jumps of SW and IMF parameters at the fronts and ISW propagation velocity.

Table 1

\begin{tabular}{|c|c|c|c|c|}
\hline No. & Station name & $\begin{array}{l}\text { Geographic } \\
\text { latitude, deg. }\end{array}$ & $\begin{array}{c}\text { Geographic } \\
\text { longitude, deg. }\end{array}$ & $\begin{array}{l}\text { Magnetometer type, } \\
\text { Sampling rate }\end{array}$ \\
\hline 1 & Barentsburg (BRB) & $70.20^{\circ}$ & $15.82^{\circ}$ & Induction, $40 \mathrm{~Hz}$ \\
\hline 2 & Lovozero (LOZ) & $67.97^{\circ}$ & $35.08^{\circ}$ & Induction, $40 \mathrm{~Hz}$ \\
\hline 3 & Uzur (UZR) & $52.17^{\circ}$ & $104.45^{\circ}$ & Induction, $40 \mathrm{~Hz}$ \\
\hline 4 & Ulaanbaatar (UBR) & $47.54^{\circ}$ & $106.53^{\circ}$ & Induction, $64 \mathrm{~Hz}$ \\
\hline 5 & Norilsk (NOR) & $69.35^{\circ}$ & $88.19^{\circ}$ & $\begin{array}{l}\text { Induction, } 64 \mathrm{~Hz} \text {; } \\
1 \mathrm{~Hz} \text { fluxgate }\end{array}$ \\
\hline 6 & Paratunka (PET) & $52.94^{\circ}$ & $158.25^{\circ}$ & $\begin{array}{c}\text { Induction, } 64 \mathrm{~Hz} ; \\
1 \mathrm{~Hz} \text { fluxgate }\end{array}$ \\
\hline 7 & Thief River Falls (THRF) & $48.03^{\circ}$ & $263.64^{\circ}$ & Induction, $20 \mathrm{~Hz}$ \\
\hline 8 & Ministik Lake (MSTK) & $53.35^{\circ}$ & $247.03^{\circ}$ & $\begin{array}{l}\text { Induction, } 20 \mathrm{~Hz} \text {; } \\
1 \mathrm{~Hz} \text { fluxgate }\end{array}$ \\
\hline 9 & Rabbit Lake (RABB) & $58.22^{\circ}$ & $256.32^{\circ}$ & $\begin{array}{c}\text { Induction, } 20 \mathrm{~Hz} \\
1 \mathrm{~Hz} \text { fluxgate }\end{array}$ \\
\hline 10 & Island Lake (ISLL) & $53.86^{\circ}$ & $265.34^{\circ}$ & $\begin{array}{c}\text { Induction, } 20 \mathrm{~Hz} ; \\
1 \mathrm{~Hz} \text { fluxgate }\end{array}$ \\
\hline 11 & Dawson (DAWS) & $64.05^{\circ}$ & $220.89^{\circ}$ & $\begin{array}{l}\text { Induction, } 20 \mathrm{~Hz} \\
1 \mathrm{~Hz} \text { fluxgate }\end{array}$ \\
\hline 12 & Fort Smith (FSMI) & $60.02^{\circ}$ & $248.05^{\circ}$ & $\begin{array}{c}\text { Induction, } 20 \mathrm{~Hz} ; \\
1 \mathrm{~Hz} \text { fluxgate }\end{array}$ \\
\hline 13 & Fort Churchill (FCHU) & $58.76^{\circ}$ & $265.92^{\circ}$ & $\begin{array}{l}\text { Induction, } 20 \mathrm{~Hz} ; \\
1 \mathrm{~Hz} \text { fluxgate }\end{array}$ \\
\hline 14 & Pinava (PINA) & $50.20^{\circ}$ & $263.96^{\circ}$ & $\begin{array}{c}\text { Induction, } 20 \mathrm{~Hz} \\
1 \mathrm{~Hz} \text { fluxgate }\end{array}$ \\
\hline 15 & Ivalo (IVA) & $68.56^{\circ}$ & $27.29^{\circ}$ & Induction, $40 \mathrm{~Hz}$ \\
\hline 16 & Kilpisjärvi (KIL) & $68.02^{\circ}$ & $20.79^{\circ}$ & Induction, $40 \mathrm{~Hz}$ \\
\hline 17 & Sodankylä (SOD) & $67.42^{\circ}$ & $26.39^{\circ}$ & Induction, $40 \mathrm{~Hz}$ \\
\hline 18 & Rovaniemi (ROV) & $66.78^{\circ}$ & $25.94^{\circ}$ & Induction, $40 \mathrm{~Hz}$ \\
\hline 19 & Oulu (OUL) & $64.52^{\circ}$ & $27.23^{\circ}$ & Induction, $40 \mathrm{~Hz}$ \\
\hline 20 & Nurmijärvi (NUR) & $60.50^{\circ}$ & $24.65^{\circ}$ & Induction, $40 \mathrm{~Hz}$ \\
\hline
\end{tabular}


Table 2

ISW parameters

\begin{tabular}{|c|c|c|c|c|c|c|c|c|c|}
\hline \multirow{2}{*}{$\begin{array}{l}\mathrm{N} \\
\mathrm{o}\end{array}$} & \multirow{2}{*}{ Date } & \multirow{2}{*}{ UT } & \multirow{2}{*}{$\begin{array}{c}\text { Normal } \\
\text { GSE }\end{array}$} & \multirow{2}{*}{$\begin{array}{l}V_{\text {ISW }} \\
\mathrm{km} / \mathrm{s}\end{array}$} & \multirow{2}{*}{$\theta\left(B_{n}\right)$} & \multicolumn{4}{|c|}{ ISW parameters } \\
\hline & & & & & & $\mathrm{cm}^{-3}$ & $\mathrm{nPa}$ & nT & $\mathrm{km} / \mathrm{s}$ \\
\hline 1 & \begin{tabular}{|l} 
June \\
21,2015
\end{tabular} & $16: 31: 31$ & $\begin{array}{l}-0.756, \\
-0.617 \\
-0.218\end{array}$ & 327 & $\begin{array}{c}83 \\
\text { (THB) }\end{array}$ & $\begin{array}{l}N \mathrm{p}_{1}=18.3 \\
N \mathrm{p}_{2}=54.8 \\
\Delta N \mathrm{p}=36.8\end{array}$ & $\begin{array}{l}P_{1}=2.57 \\
P_{2}=9.47 \\
\Delta P=6.9\end{array}$ & $\begin{array}{l}B_{1}=(-1.39,+0.88,+1.25) \\
B_{2}=(-3.27,+1.5,+2.87) \\
B_{1 \mathrm{t}}=2.07 \\
B_{2 \mathrm{t}}=4.6\end{array}$ & $\begin{array}{l}V_{\mathrm{p}} 1=285 \\
V_{\mathrm{p}} 2=345 \\
\Delta V_{\mathrm{p}}=60\end{array}$ \\
\hline 2 & \begin{tabular}{|l} 
June \\
22,2015
\end{tabular} & $05: 35: 59$ & $\begin{array}{l}-0.918, \\
-0.394, \\
0.0348\end{array}$ & 440 & $\begin{array}{c}78 \\
(\mathrm{THC})\end{array}$ & $\begin{array}{l}N \mathrm{p}_{1}=11.5 \\
N \mathrm{p}_{2}=25 \\
\Delta N \mathrm{p}=3.5\end{array}$ & $\begin{array}{l}P_{1}=2.56 \\
P_{2}=8.69 \\
\Delta P=6.13\end{array}$ & $\begin{array}{l}B_{1}=(-5,+7,-1.5) \\
B_{2}=(-7.5,13.5,-1) \\
B_{1 \mathrm{t}}=8.73 \\
B_{2 \mathrm{t}}=15.5\end{array}$ & $\begin{array}{l}V_{\mathrm{p}} 1=344 \\
V_{\mathrm{p}} 2=430 \\
\Delta V_{\mathrm{p}}=86\end{array}$ \\
\hline 3 & $\begin{array}{l}\text { June } \\
22,2015\end{array}$ & 18:08:21 & $\begin{array}{l}-0.919, \\
-0.392, \\
-0.039\end{array}$ & 712 & $\begin{array}{c}78 \\
(\mathrm{~W})\end{array}$ & $\begin{array}{l}N \mathrm{p} 1=15 \\
N \mathrm{p} 2=60 \\
\Delta N \mathrm{p}=45\end{array}$ & $\begin{array}{l}P 1=4.11 \\
P 2=50.10 \\
\Delta P=46.99\end{array}$ & $\begin{array}{l}B_{1}=(-2.02,+1.2,-8.13) \\
B_{2}=(+8,-25,-22) \\
B_{1 \mathrm{t}}=8.46 \\
B_{2 \mathrm{t}}=26.4\end{array}$ & $\begin{array}{l}V_{\mathrm{p}} 1=450 \\
V_{\mathrm{p}} 2=700 \\
\Delta V_{\mathrm{p}}=250\end{array}$ \\
\hline
\end{tabular}
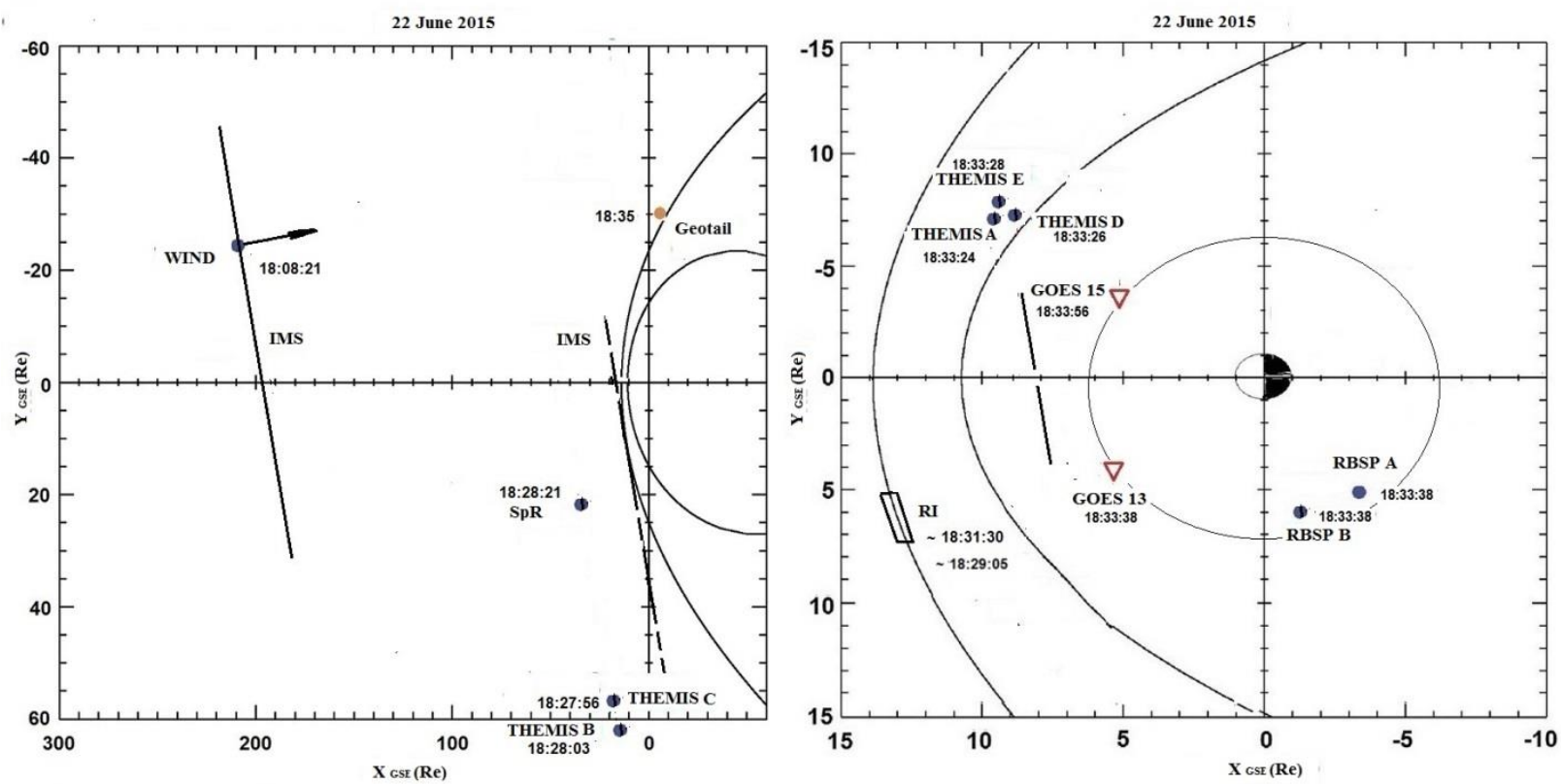

Figure 4. Locations of satellites during the recording of the June 22, 2015 ISW. The arrow shows the direction of the wave normal at 18:08:21 UT. The dashed line parallel to the ISW front denotes the region of the interaction between ISW and bow shock wave (BSW); RI is the region of interaction. Location of BSW as derived from OMNI data [https://cdaweb.sci.gsfc.nasa.gov/cdaweb/istp_public/]; location of the magnetopause is calculated by the model [Lin et al., 2010] 

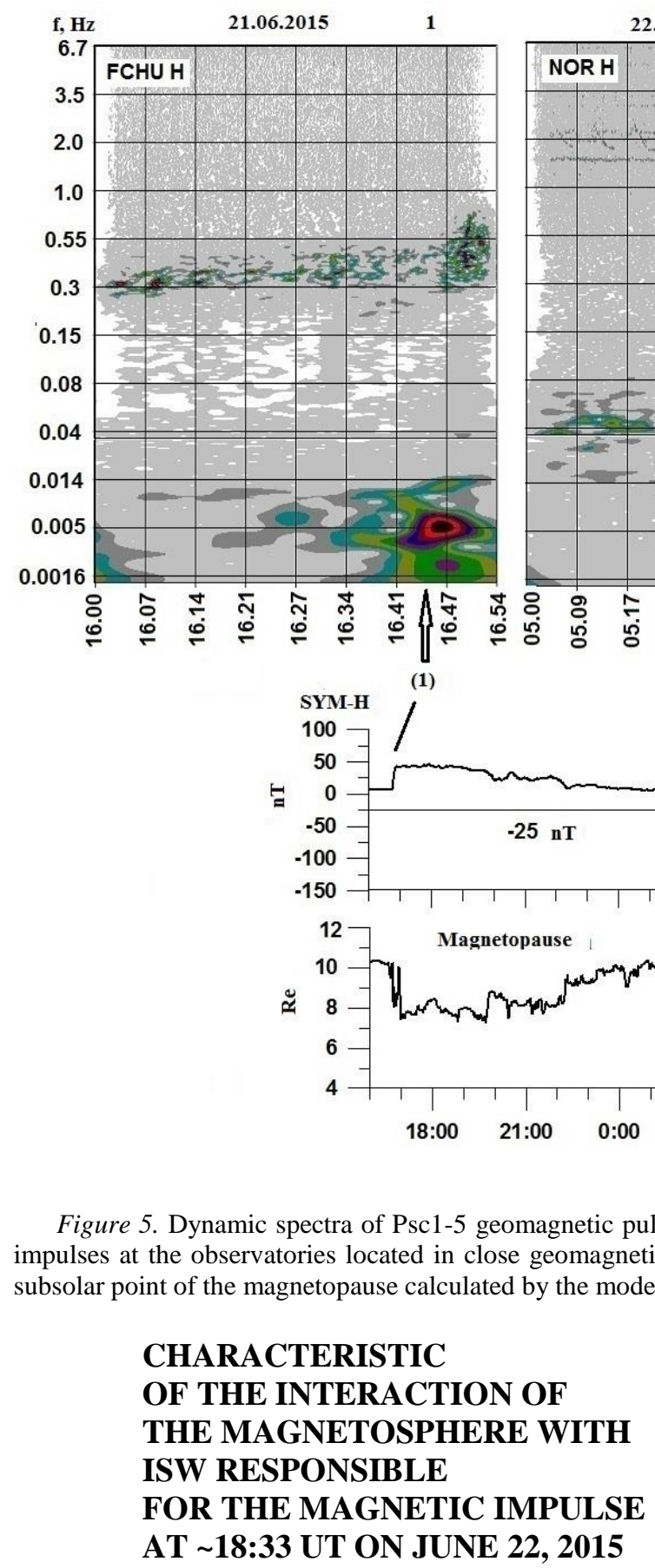

Figure $6 a, b$ shows that the SpR and THB satellites, which were in SW at a distance from each other (in GSE) of $\sim 38 R_{\mathrm{E}}$ in the $y$ coordinate and at $\sim 7 R_{\mathrm{E}}$ in the $x$ coordinate (Figure 4 ), recorded large and sudden increases in the SW stream (by $48 \cdot 10^{8} \mathrm{~cm}^{-2} \mathrm{~s}^{-1}$ ) and IMF modulus (by $20 \mathrm{nT}$ ) at $\sim 18: 28: 21$ and 18:28:05 UT at the front of ISW for $2 \mathrm{~s}$. The ISW velocity was $712 \mathrm{~km} / \mathrm{s}$, and the wave normal defined by the geometrical method with the aid of six spacecraft had GSE coordinates $n=(-0.919$, $-0.392,-0.039$ ) (indicated by an arrow in Figure 4).

Let us identify the region of the first ISW-BSW interaction. Given the orientation of the normal and the fact that the ISW moving at a velocity of $712 \mathrm{~km} / \mathrm{s}$ crossed the SpR satellite at 18:28:21 UT, we can assume that the ISW interacted with the BSW at 15 MLT (Figure 4). Then, the ISW covered the distance from the satellite to the BSW of $\sim 21 R_{\mathrm{E}}$ in $\sim 182 \mathrm{~s}$. Hence, the ISWBSW interaction occurred at $\sim 18: 31: 30$ UT. In Figure 4, the interaction region is denoted by a rectangle RI.

The high-speed SW stream caused BSW to deform; as a result the THA, THD, THE satellites, located in the magnetosheath before the ISW arrival, were sequentially affected by SW (at 18:33:47, 18:33:54, and 18:33:57 UT respectively) [Cully et al., 2008].

The magnetosphere-ISW interaction also led to a rapid shift of the magnetopause to Earth, as can be derived from GOES-13, -15 observations [https://satdat.ngdc.noaa. gov/sem/goes/ data/full]. In the geostationary orbit, an increase in the magnetic field component $H_{\mathrm{p}}$, which is northward and perpendicular to the plane of the satellite's orbit, i.e. close to the vertical component in the GSE system, by more than $50 \mathrm{nT}$ (magnetospheric compression), was recorded by GOES-13 at 18:33:38 UT, and by GOES15 at 18:33:56 UT (Figure $6 f, g$ ). Such a difference in the arrival times of signals at the satellites means that the direction of propagation of the disturbance in the magnetosphere has an essential dusk-dawn component. After a short interval of compression, the $H_{\mathrm{p}}$ component changed sign to $-200 \mathrm{nT}$. This variation arises from the fact that the 

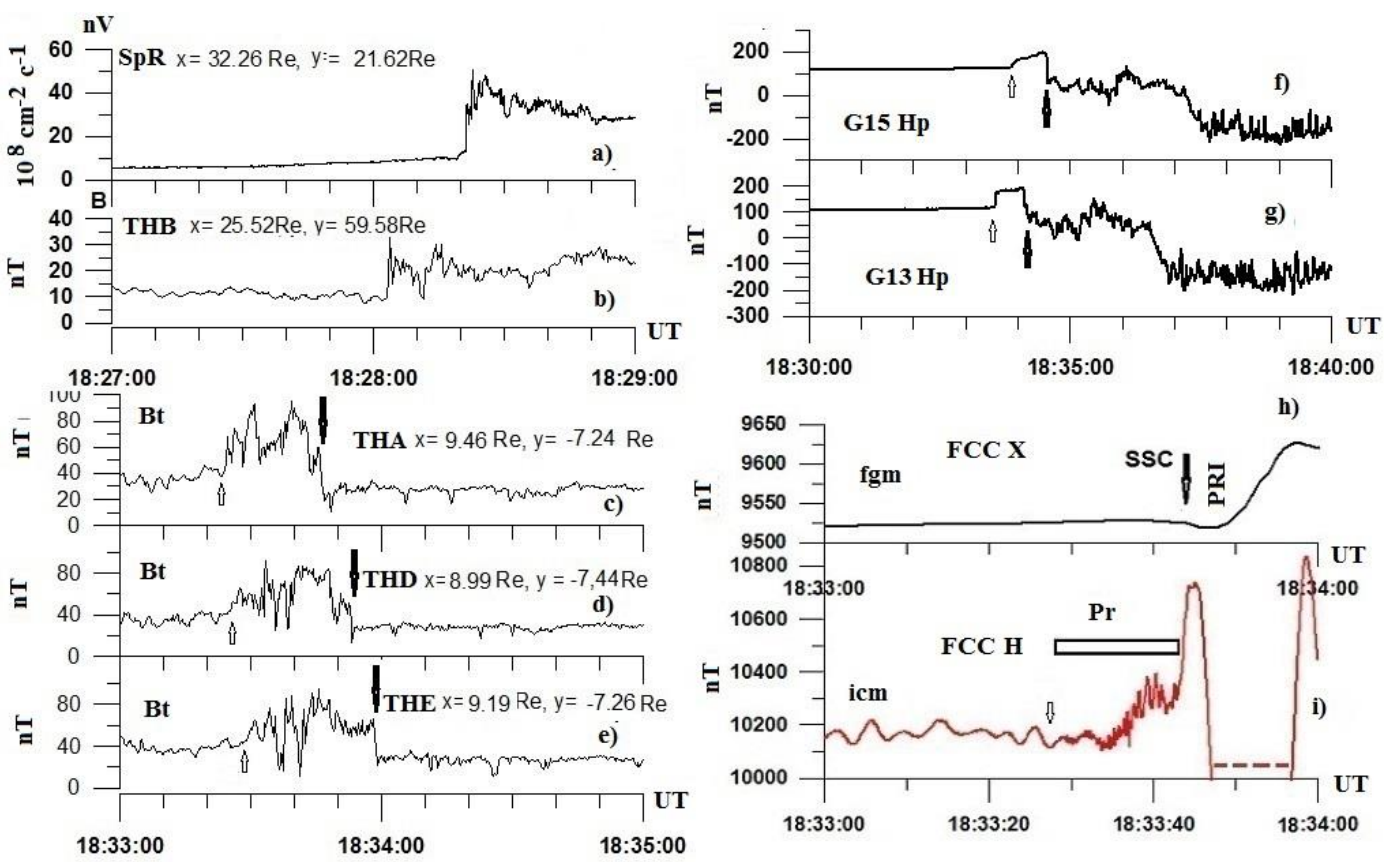

Figure 6. Variations in parameters of SW, IMF, magnetic field in the magnetosheath, geomagnetic field in the geostationary orbit and ground FCC observatory near the noon meridian. Satellite coordinates are given in the plots: SW stream variations as derived from SpR measurements $(a)$; IMF $B$ modulus variations as deduced from THB measurements $(b) ; B$ variations in the magnetosheath according to THA measurements $(c)$; the same for the THD satellite $(d)$; the same for the THE satellite (white arrows on the panels indicate the occurrence of the disturbance in the satellites, dark arrows on panels $c-e$ denote the passage of the satellites through SW due to the earthward displacement of BSW and magnetopause $(e) ; H_{\mathrm{p}}$ variations in the synchronous orbit (light arrows indicate the occurrence of the magnetic impulse in GOES-13 and GOES-15, thick arrows mark the occurrence of the variations associated with the passage of the magnetopause through the satellites) $(f, g)$; geomagnetic field variations recorded by fluxgate (fgm, $1 \mathrm{~Hz}$ sampling rate) and induction (icm, $20 \mathrm{~Hz}$ sampling rate) magnetometers in the FCC observatory ( $h$, $i$ ). The PRI arrow denotes the occurrence of $x$-component variations - the occurrence of the preliminary reverse impulse; Pr is the precursor of the magnetic impulse (high-frequency oscillations of the falling frequency)

current layer of the magnetopause shifted to Earth at a distance of less than $6.6 R_{\mathrm{E}}$, which agrees well with the model calculations (Figure 5,c). The time difference between indications of the passage of the magnetopause according to the data from the geostationary satellites, located at approximately equal distances from the Earth-Sun line in the dusk and dawn sectors, is consistent with the fact that the front of the disturbance in SW and transition region propagates from the evening side of the magnetosphere (Figure 4).

Let us analyze ground magnetic observations made at the high-latitude FCC observatory, located near the noon meridian, with magnetometers of two types fluxgate and induction (Figure $6, h, i$ ). The magnetogram from the fluxgate magnetometer (1 s sampling rate) shows that the magnetic field variation consists of a preliminary reverse impulse (PRI) with an amplitude of $\sim 15 \mathrm{nT}$ (the 18:33:42 UT arrow in Figure $6, h$ ) and a sharp positive increase in the magnetic field at 18:33:49 UT (magnetic impulse). The $x$ component on the INTERMAGNET magnetogram (1 min sampling rate) from Fort Churchill observatory varied from $9517 \mathrm{nT}$ at 18:33 to $\sim 10188 \mathrm{nT}$ at 18:36 UT. The induction magnetometer oscillogram from 18:33:27 to $18: 33: 44$ UT (Figure 6, $i$ ) displays an oscillation packet, denoted by Pr, with increasing period by its end. The onset of oscillations in the packet (arrow in Figure 6, $i$ ) is clearly ahead of the onset of the magnetic impulse. Parkhomov et al. [2014, 2017] considered the packet as a precursor of the sudden impulse, which could be classified as SSC. Note that in our case the magnetic impulse occurs during the development of the magnetic storm main phase. Nevertheless, it also has a corresponding precursor in geomagnetic pulsations.

Thus, the response in the geomagnetic field to the third ISW comprises a precursor in the form of the oscillation packet with a falling frequency in the frequency range $0.5-11 \mathrm{~Hz}$, which occurs before the magnetic impulse - the beginning of a sharp rise in the $H$ component and preliminary reverse negative impulse of the geomagnetic field, used to identify the onset of the magnetic impulse on Earth. It is interesting that the precursor also occurs before the beginning of the sharp change of the geomagnetic field in the synchronous orbit. We will discuss this feature later.

\section{SPATIAL FEATURES OF DYNAMIC SPECTRA OF BURST OF OSCILLATIONS (PRECURSOR)}

Figure 7, $a, b$ shows dynamic spectra of a precursor in the $D$ component at CARISMA observatories (DAWS, FCHU), located near the noon meridian during recording of the third magnetic impulse, and at the Para- 
tunka observatory (PET, Kamchatka) [Shiokawa et al., 2010] in the morning. The spectra were calculated using the standard function Spectrogram of the MATLAB package to estimate the power spectral density with preliminary excluded linear trend (Figure 7,a), and the spectral-temporal analysis program (SWAN) [Levshin et al., 1968] (Figure 7, b). The spectra between 18:33:30 and 18:33:50 UT exhibit a burst in the frequency range $0.5-8 \mathrm{~Hz}$. It can be seen that the oscillations with the falling frequency began simultaneously at the CARISMA observatories at $\sim 18: 33: 27$ UT at a frequency of $\sim 8$ $\mathrm{Hz}$. At the end of the packet, the frequency falls to $\sim 0.5$ Hz. Stations of the CARISMA network were located in the noon sector at that time. At PET, the upper frequency was $\sim 4 \mathrm{~Hz}$.

Similar spectra of signal-precursors of the magnetic impulse were observed in all CARISMA observatories located in the daytime sector of the magnetosphere (Figure 7,c).

The main features of the spectra obtained by the two methods are the simultaneous generation of the signals considered, their similar duration in all the observatories, frequency fall by the end of the burst, and spectral resonance structure (SRS). On SWANograms, SRS is more pronounced. The position of spectral maxima varies in frequency from observatory to observatory. In the spectrum of the $D$ component from PET, which is in the dawn sector (8.30 MLT) during the recording of the burst, the upper frequency of the burst $(\sim 4 \mathrm{~Hz})$ is lower than that at all other observatories (Figure $7 a, b$ ). The main signal energy is in $0.4-5 \mathrm{~Hz}-$ the frequencies of the ionospheric Alfvén resonator (IAR) [Belyaev et al., 1989; Polyakov, Rapoport, 1981 ] and in $0.15-0.3 \mathrm{~Hz}-$ the frequencies of the above-the-ionosphere Alfvén resonator [Dovbnya et al, 2013].

Similar regularities in the dynamic spectra of the precursor of the third magnetic impulse are observed at the observatories in the dusk sector of the magnetosphere (Finnish meridional chain of magnetometers and the magnetometer of the Polar Geophysical Institute in Barentsburg) (Figure $8 b, c$ ). Here, as well as on the day side of the magnetosphere, onsets of the burst and durations of the packet, frequency fall by the end of the packet, and resonance structure coincide at the observatories. The frequency range of the bursts is wider in the $H$ component - from 0.5 to $11 \mathrm{~Hz}$. In the $D$ component, the frequency range is narrower and the upper frequency does not exceed $\sim 5.6 \mathrm{~Hz}$. The frequency of spectral maxima depends on the location of observatory. The difference in the bandwidth between the observatories may be due to the difference in the sampling rate of induction magnetometers: $20 \mathrm{~Hz}$ in the CARISMA network and $40 \mathrm{~Hz}$ in the Finnish meridional network.

At KIL, IVA, SOD and most obviously at OUL, the burst of geomagnetic pulsations begins at a frequency of $\sim 11 \mathrm{~Hz}$, and the first spectral maximum occurs at $10 \mathrm{~Hz}$, as in the auroral observatory NOR, which is located near the midnight meridian. In the $D$ component, the northernmost station Barentsburg recorded signal intensity attenuation. A similar regularity is observed in the pair of observatories Norilsk - Ulaanbaatar in the nearmidnight hours (Figure 9).
The spectral maximum of the bursts at $\sim 3.1 \mathrm{~Hz}$ is observed at all observatories of the Finnish chain in the $H$ component and at the dayside observatories. The $D$ component at all observatories of the dusk sector exhibits a spectral maximum at $1.2 \mathrm{~Hz}$. At the same frequency, there is a spectral maximum at the observatories near the midnight meridian (Figure 9).

The same regularities in the dynamic spectra of the burst of geomagnetic pulsations (magnetic impulse precursor) are seen at mid- and high-latitude observatories in the nighttime sector of the magnetosphere $\left(88^{\circ}-\right.$ $106^{\circ}$ ) (Figure 9). In Norilsk, the burst structure is similar to those in the dusk sector and the highest frequency also reaches $\sim 11 \mathrm{~Hz}$.

Let us summarize the observed properties of the pulsation burst - the precursor of the third magnetic impulse in the events of interest.

1. Bursts of pulsations are observed globally in the frequency range from 0.2 to $11 \mathrm{~Hz}$.

2. At widely spaced observatories, onsets of bursts and durations of the oscillation train roughly coincide; the oscillation frequency falls by the end of the packet.

3. All the observatories detect SRS.

\section{RESULTS OF NARROWBAND FILTERING}

Signal delays at widely spaced observatories are determined after applying digital filtering in a narrow frequency band $\Delta f=0.2 \div 0.8 \mathrm{~Hz}$ (Figure 10,a-c). The filters have been developed based on Marmet's algorithm that does not distort the phase signal characteristic [Marmet, 1979].

It can be seen that the oscillograms of filtered signals confirm a frequency fall by the end of the burst the burst begins at high frequencies, then at ever lower ones. It is also confirmed that the preliminary impulse occurs in advance (fragments of fluxgate magnetometer records are presented in Figure 10, b). Filtered records also support the described signal frequency dynamics observed in dynamic spectra from the same observatories (Figure 10,c). Filtered oscillograms from longitudinally spaced observatories (the greatest distance is $\sim 105^{\circ}$ ) at two central frequencies of 0.5 and $1.2 \mathrm{~Hz}$ are shown in Figure 11 with high temporal and amplitude resolution to determine signal propagation delay.

To assess the possible signal propagation delay between the longitudinally spaced observatories, we have compared filtered signals at two frequencies. Figure 11 indicates that there are no delays at 0.5 and $1.2 \mathrm{~Hz}$ (in [Parkhomov et al., 2017], the delay between stations of daytime and nighttime sectors is $4 \mathrm{~s}$ ).

\section{RELATIONSHIP BETWEEN PRECURSOR AND COSMIC NOISE ABSORPTION}

The development of sudden magnetic impulses is often accompanied by precipitation of energetic electrons causing absorption of cosmic radio noise (riometer absorption) [Nishida, 1980].

Let us examine features of the relationship between the burst-precursor in geomagnetic pulsations and cosmic noise absorption, using $10 \mathrm{~s}$ data acquired with the OUL riometer and magnetometers. 

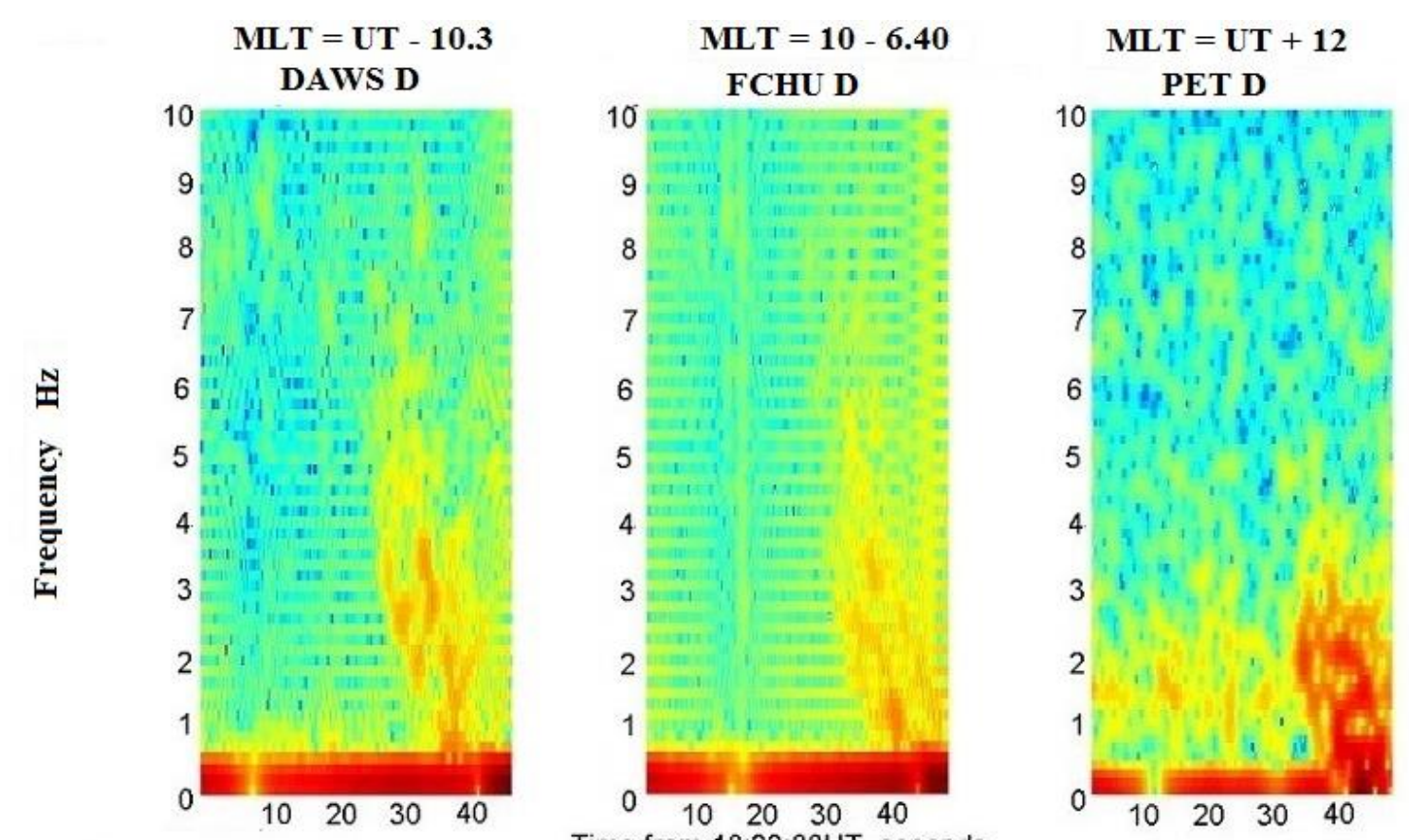

a)

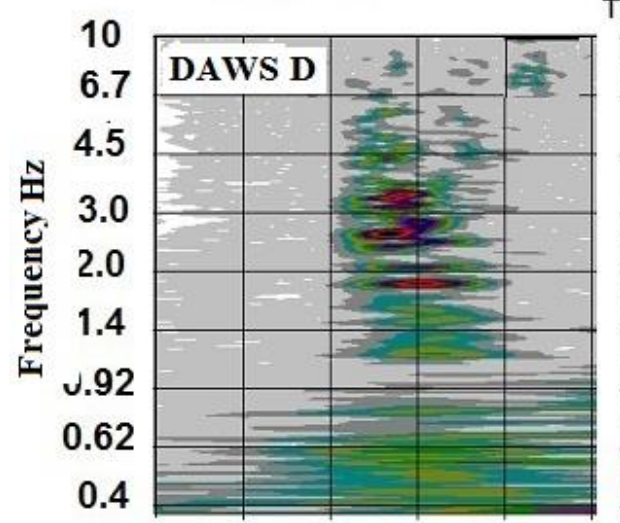

Time from 18:33:00UT, seconds
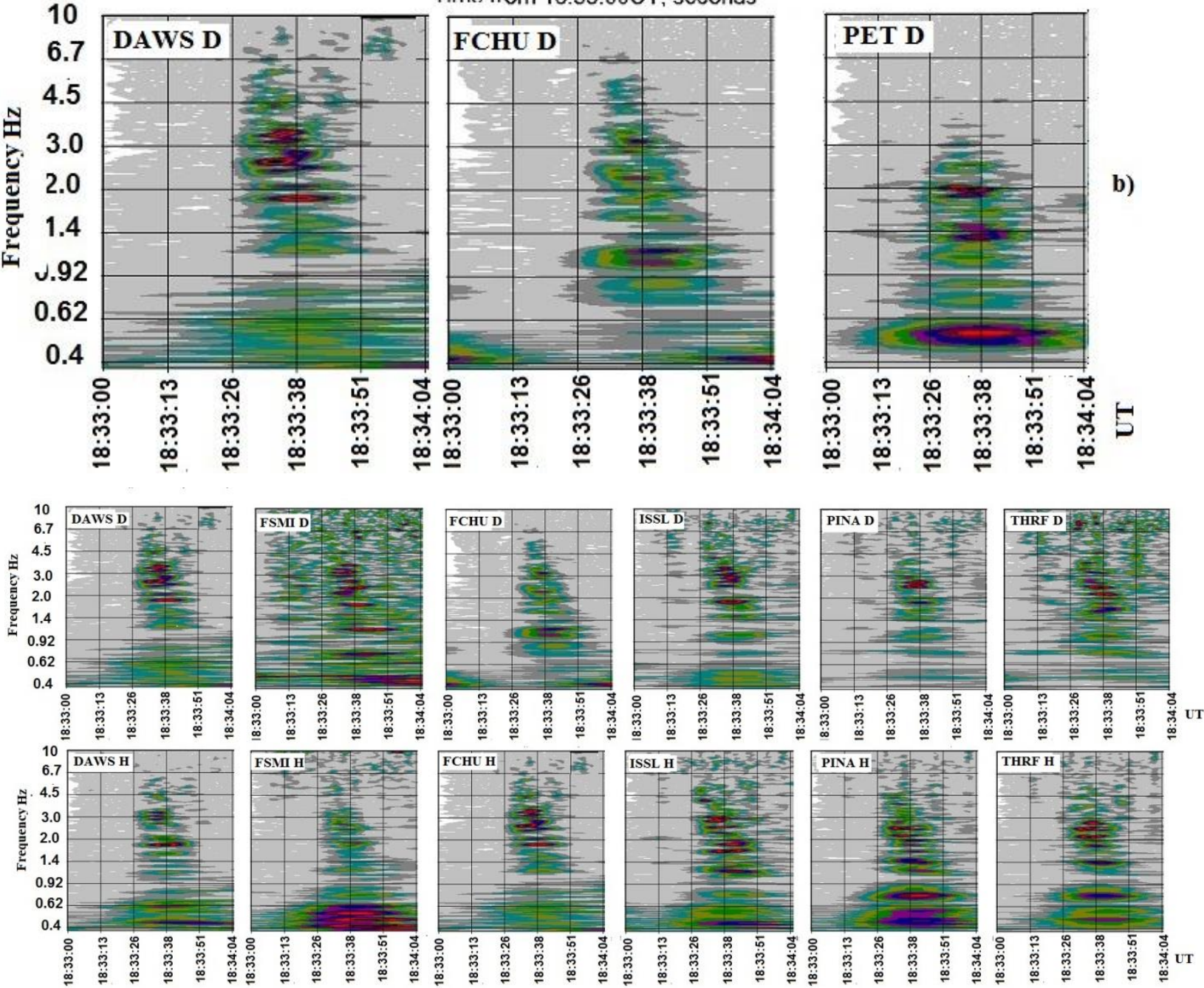

Figure7. Dynamic spectra of the burst-precursor of the third magnetic impulse, recorded by ground-based observatories, which were calculated using the software packages MATLAB $(a)$ and SWAN $(b)$; spectra obtained with SWAN according to data from the observatories of the daytime sector (CARISMA network) on June 22, 2015 (c) 

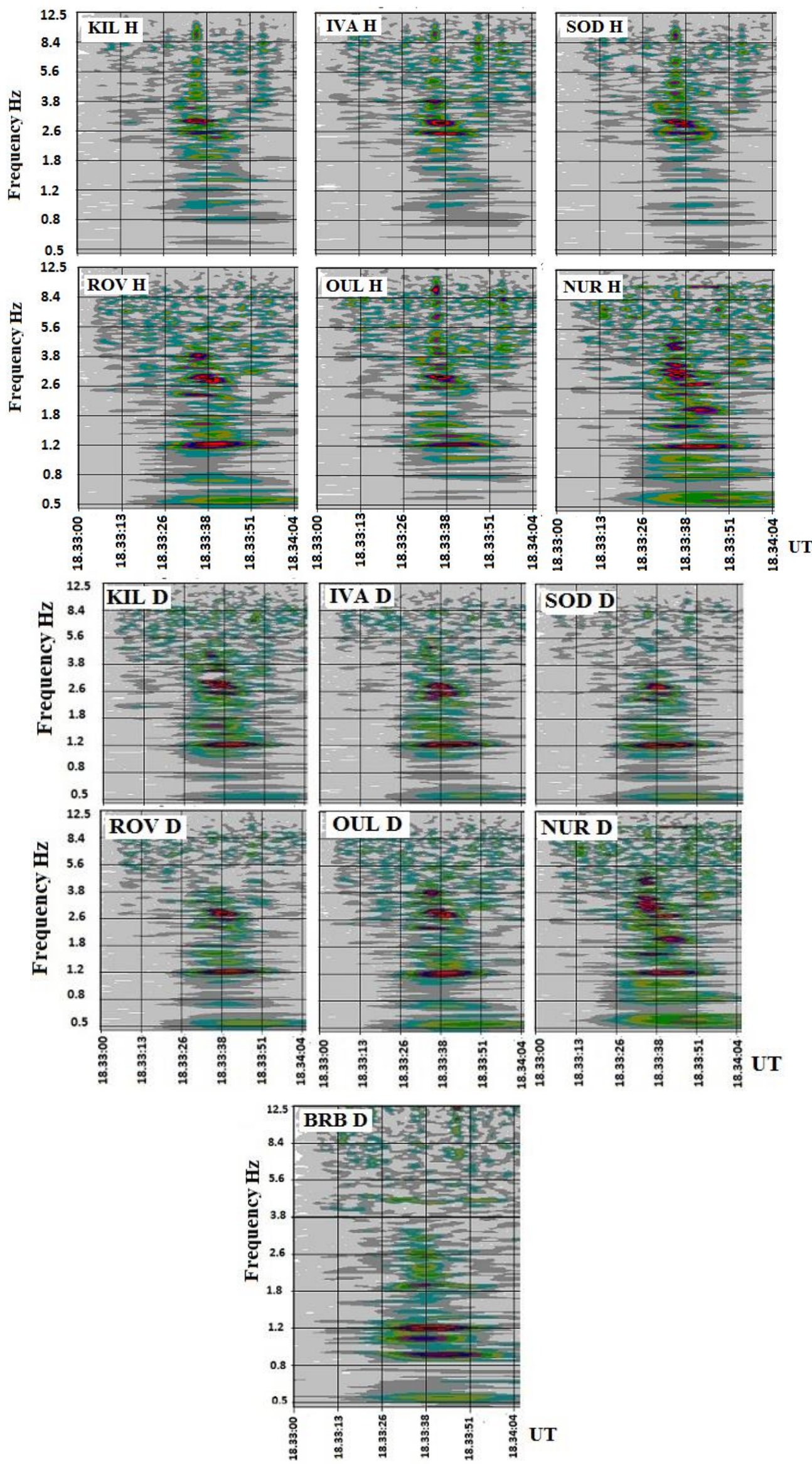

Figure 8. Dynamic spectra of the $H(a)$ and $D(b)$ components at the observatories of the dusk sector of the magnetosphere (Finnish meridional chain of magnetometers); $D$ component $(c)$ as derived from the data obtained with the magnetometer of the Polar Geophysical Institute in Barentsburg 

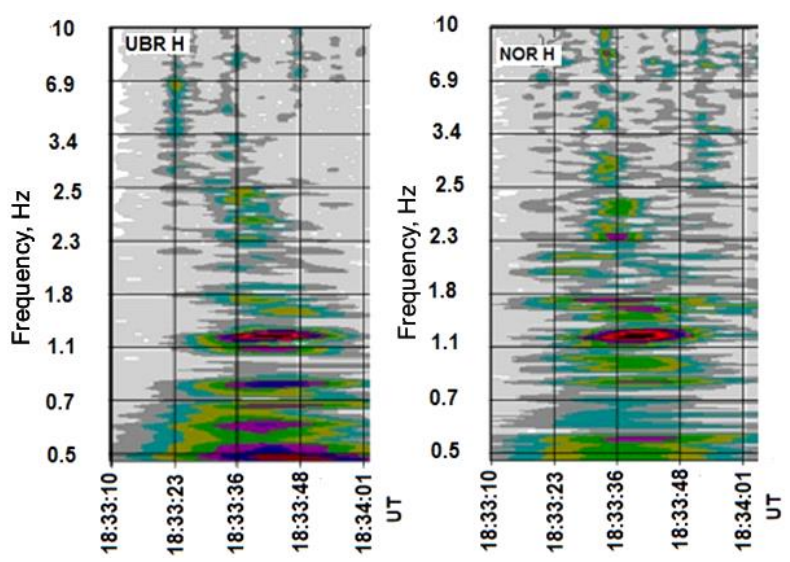

Figure 9. Dynamic spectra of pulsations at mid-latitude and high-latitude observatories of nighttime sector of the magnetosphere in Ulaanbaatar and Norilsk
Figure 12 presents fragments of riometer $(a)$, fluxgate $(b)$ and induction $(c)$ magnetometer records and oscillograms of signals filtered in two frequency ranges, with a central frequency of 0.5 and $4.2 \mathrm{~Hz}$ of OUL during the local evening hours (MLT 19:30). The time of observation of the packet of damped oscillations with SRS is marked with a rectangle. The spectrum of these oscillations is displayed in Figure 8.

Figure 12, $c$ (oscillogram from the induction magnetometer) shows that from 18:33:28 UT there is a train of magnetic field oscillations acting as a precursor of the magnetic impulse (rectangle). At 18:34:00 UT, the preliminary reverse impulse (PRI) begins (Figure 12, b) whose onset coincides with the onset of auroral absorption (Figure 12,a), caused by energetic electron precipitation due to the onset of magnetospheric compression. It is important that the absorption enhancement begins after the end of the packet at 18:34:00 UT.
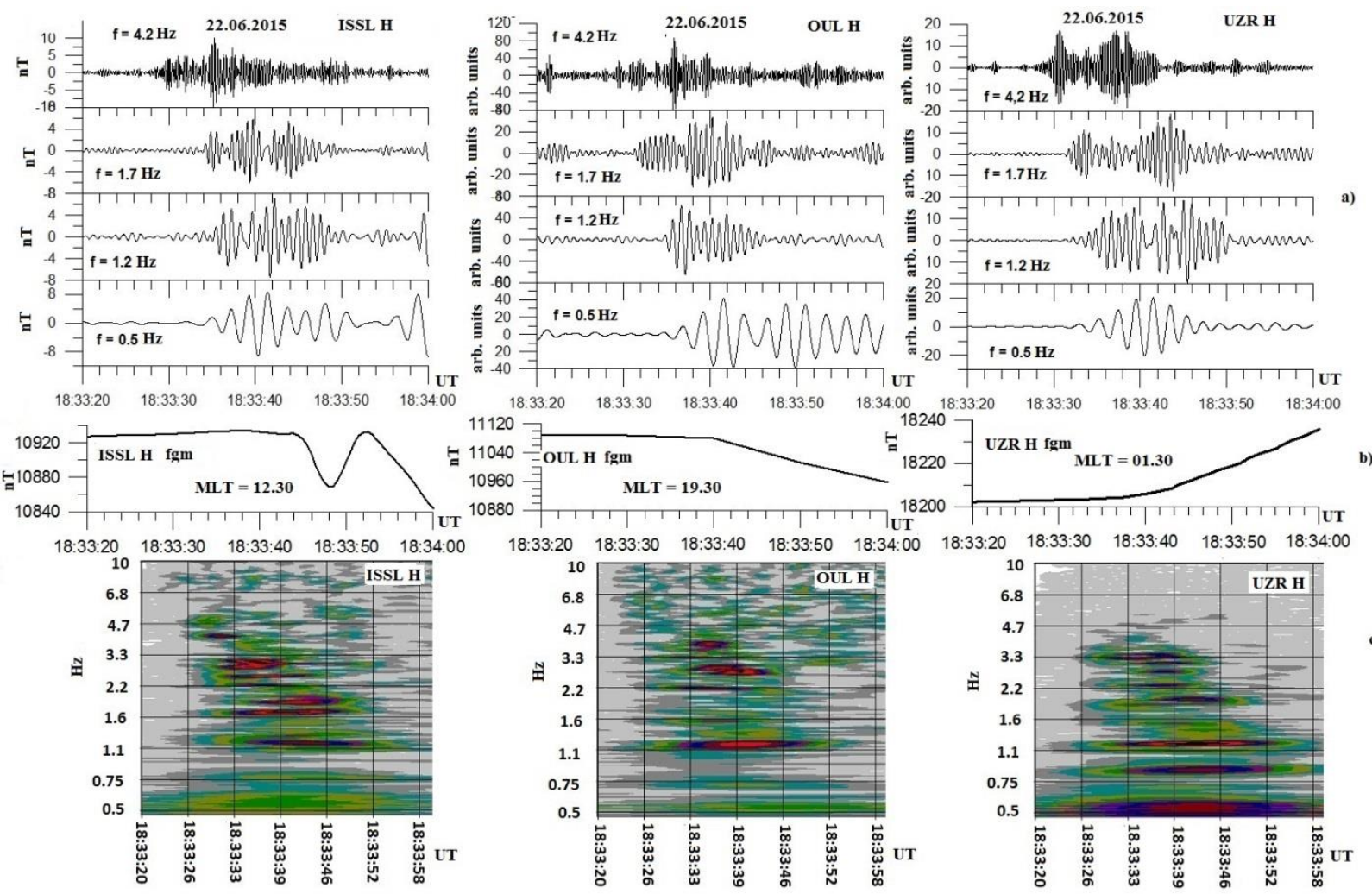

Figure 10. Packet oscillograms filtered by narrowband filters at 4.2, 1.7, 1.2, and $0.5 \mathrm{~Hz}(a)$; a fragment of magnetograms obtained with fluxgate magnetometers, with the local time of observatories indicated $(b)$; dynamic spectra calculated by SWAN $(c)$ 

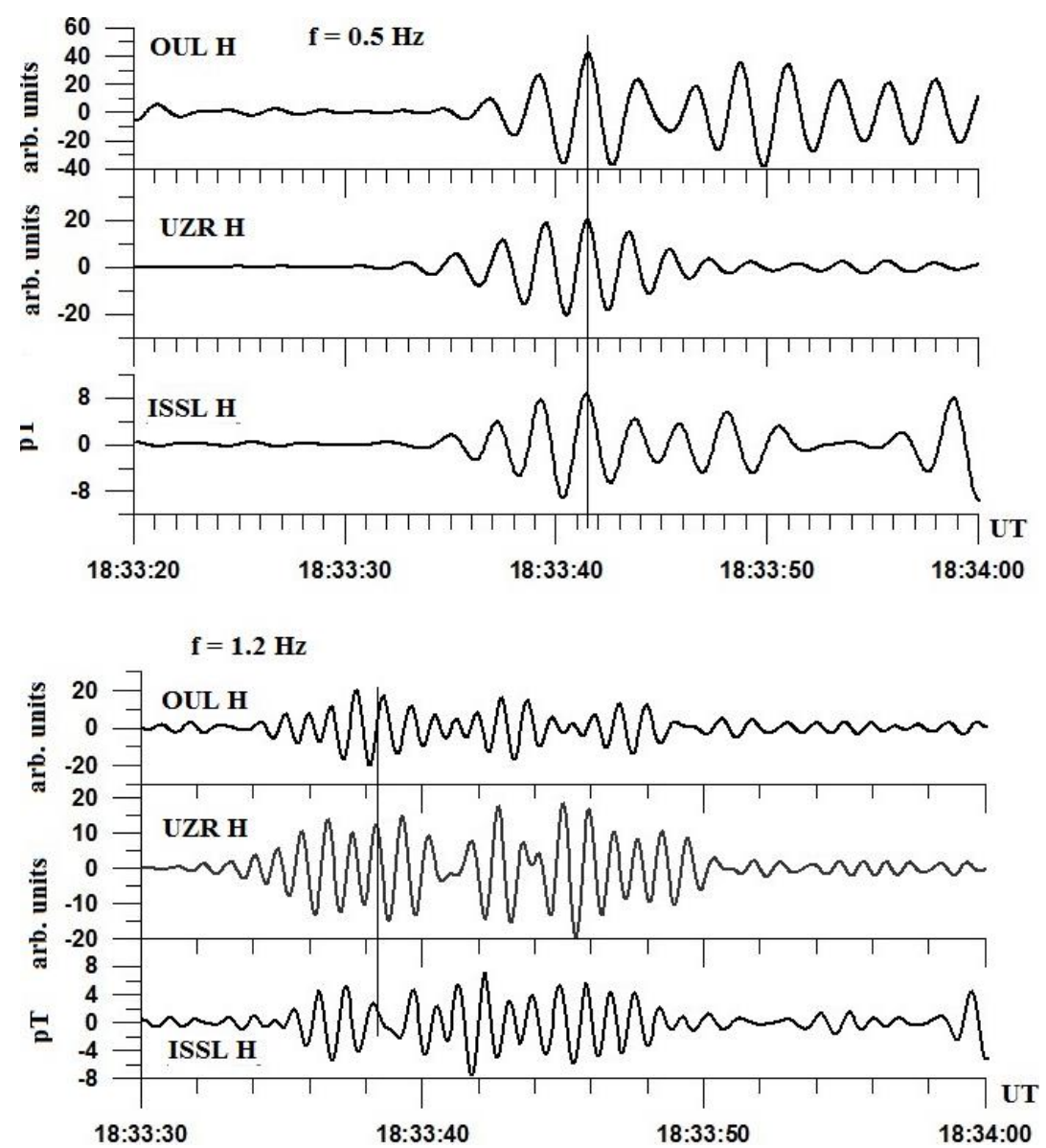

Figure 11. Oscillograms of filtered signal at two frequencies according to data from observatories at three longitudes

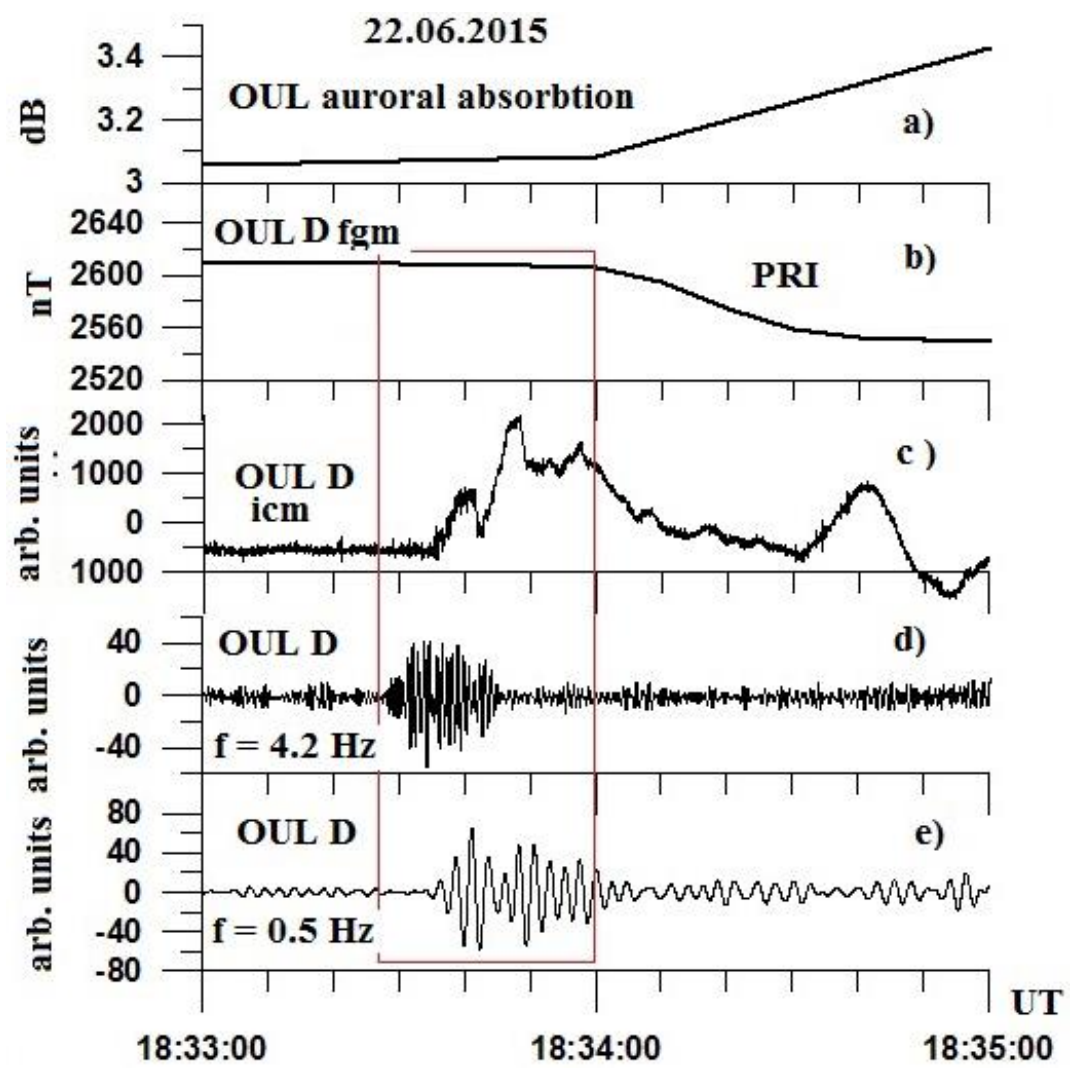

Figure 12. Fragments of riometer recording $(a)$, fluxgate magnetometer magnetogram $(b)$, induction magnetometer oscillogram $(c)$, oscillogram of filtered signal with central frequencies of $4.2 \mathrm{~Hz}(d)$ and $0.5 \mathrm{~Hz}(e)$ at OUL in the dusk sector 
These data show that the oscillation packet occurs about thirty seconds in advance of the beginning of the riometer absorption and PRI. Such a relationship between the oscillation burst in the hertz range and the onset of riometer absorption is observed at CARISMA observatories during the local daytime hours (data not shown).

\section{RESULTS AND DISCUSSION}

We believe that the above information is convincing evidence of the existence of a magnetic impulse precursor in the form of a burst of pulsations in the range $~ 0.5-11$ Hz. It should be noted that this event differs in some aspects from that analyzed, for one, by Parkhomov et al. [2017]. The authors assume that such a burst is a consequence of propagation of an electromagnetic ion-cyclotron wave from the magnetospheric compression region, where during the compression the anisotropy of energetic protons usually sharply increases (see, e.g., [Olson, Lee, 1983]) Generation of ion-cyclotron instability occurs first on the day side and then, due to propagation of the compression wave to the magnetospheric tail, can shift to the night side. There really was a delay in recording the oscillation train from the day side to the night side (up to 4 s) [Parkhomov et al., 2017]. The case we considered is characterized by the absence of significant delays in the transition from the day side to the night side.

In this case we can assume that signal propagation in the Earth - ionosphere waveguide is similar to that occurring during Q bursts, associated with lightning discharges [Hayakawa et al., 2002; Nickolaenko, Hayakawa, 2002].

The analogy with Q bursts is attested by the oscillation spectrum in its high-frequency range. Note that Fedorov et al. [2014] proposed a mechanism of formation of geomagnetic field response in the hertz range to the lightning discharge as a burst whose spectrum contains a resonance structure. We assume that the lightning discharge in our case can be the electromagnetic impulse caused by abrupt particle precipitation to the ionosphere from the magnetospheric compression region in the primary ISW-magnetosphere interaction. This precipitation and its related pulsed modification of ionospheric parameters may be short-term and cause no noticeable consequences such as an increase in riometer absorption and formation of magnetic PRI. The latter are likely to be due to particle precipitation from the compressed magnetosphere after establishment of its new configuration.

Since energetic electrons along field lines precipitate for seconds, the precursor we considered may serve as an indicator of the first ISW-magnetosphere interaction. Of course, the proposed interpretation is preliminary and needs to be verified and stronger evidence.

The precipitation from the magnetospheric compression region may be caused by cyclotron instability. Indeed, synchronously with the magnetospheric compression recorded by GOES (Figure $6, f, g$ ), these satellites detected an increase in electron flows in a wide energy range (data not presented here), which, along with an increase in the transverse anisotropy of particle fluxes associated with magnetic field compression, stimulates the development of the instability.

As has been noted, the precursor in the case of interest was observed earlier than the magnetic field compression in the geosynchronous orbit. This is consistent with the assumption that the cause of the precursor is precipitation of particles immediately after the first ISW-magnetopause interaction, which occurred when the magnetopause still was at $\sim(9 \div 10) R_{\mathrm{E}}$. The precursor we examined differs from the precursor studied in [Parkhomov et al., 2017] also by the fact that at low frequencies of $<2 \mathrm{~Hz}$ there is a signal delay relative to the high-frequency range of the spectrum.

The cause of such frequency variance remains unclear, and we restrict ourselves here to stating this fact. Thus, although the set of the data considered definitely indicates the presence of a new element in the development of the phenomena associated with magnetic impulses (see also [Parkhomov et al., 2014, 2017; Parkhomov et al., 2016]), its nature remains largely unclear. We plan to carry out further research.

\section{CONCLUSION}

We have compared the response in the geomagnetic pulsations accompanying the development of three sudden impulses of the geomagnetic field, which, in turn, was caused by the interaction between the magnetosphere and three ISW on June 21-22, 2015. The first two impulses were generated by ISW that propagated with a velocity of less than $500 \mathrm{~km} / \mathrm{s}$. Jumps of the dynamic pressure at the fronts of these waves were $\sim 7 \mathrm{nPa}$. Magnetic field impulses corresponding to these ISW were followed by broadband bursts of Psc1-5 pulsations whose morphological characteristics and excitation mechanisms have been extensively described in numerous papers, reviews, and monographs.

The third ISW had a much higher velocity (720 $\mathrm{km} / \mathrm{s}$ ) and a much higher pressure jump in the wavefront $(\sim 50 \mathrm{nPa})$. The respective impulse of the geomagnetic field has an amplitude of $\sim 110 \mathrm{nT}$ and developed against the background of the geomagnetic storm main phase. It is shown that this burst was preceded by the so-called preliminary reverse impulse, in front of which, in turn, there was a train of $\sim 20 \mathrm{~s}$ geomagnetic pulsations. The spectrum of this pulsation train had the form of pulsation burst in the $0.5-11 \mathrm{~Hz}$ frequency range with a pronounced resonance structure and a frequency fall by the end of the burst. In this case, there were no significant delays in recording of this burst at widely spaced stations in different MLT sectors.

The analysis of this and some other events [Parkhomov et al., 2014, 2017; Parkhomov et al., 2016] shows that in the cases of magnetospheric compression during the interaction of ISW with a sharp front and high jumps of plasma parameters at the fronts, the first indication of such interaction can be not the sudden magnetic impulse as such, but the above broadband burst of geomagnetic pulsations in the hertz range. 
ACE, WIND, Geotail, Cluster, THEMIS, and NOAA GOES-13, -15 data have been obtained from the NASA CDAWeb database. We are grateful to supervisors, developers of the instruments, and supervisors of the experiments conducted with these satellites for providing us with the data. We thank I.R. Mann, D.K. Milling and other members of the CARISMA team for providing data, (CARISMA is managed by the University of Alberta and funded by the Canadian Space Agency). We also thank researchers from the Space Research Institute for providing Spektr-R satellite data. The data of induction magnetometers of the Uzur and Norilsk observatories were obtained using the equipment of the magnetometric complex of Center for Common Use «Angara» of Institute of Solar-Terrestrial Physics SB RAS [http://ckp-rf.ru/ckp/3056/]; Barentsburg observatory data, by the Polar Geophysical Institute; and data from the Finnish network of induction magnetometers and riometers, by Sodankylä Geophysical Observatory. The work of V.A. Parkhomov was supported by RFBR grants No.16-02-00669 and No. 18-55-52006 MNTa; the work of B. Tsegmed was made possible by a grant from the Academy of Sciences of Mongolia SHUAG_2017/17 and by the project of the Ministry of Education, Science and Sport of Mongolia SHUSS2017/65; the work of S.Yu. Khomutov was supported by Project No. AAAA-A17-117080110043-4 from August 01, 2017; the work of N.L. Borodkova was partially supported by RFBR grant No.16-02-00669 and 1602-00125; the work of A.G. Yahnin and T. Raita was supported by grant from the Academy of Sciences of Finland No. 294931; the work of A.A. Mochalov was carried out under state task No. AAAA A 18118012490100-7. Measurements made using the induction magnetometer of Geophysical Observatory Paratunka are carried out under the agreement on academic exchange between IKIR FEB RAS and National Industrial Research Institute of Nagoya (Japan) with support of the PWING project (JSPS KAKENHI 16H06286).

We thank V.G. Eselevich, A.S. Leonovich, and A.G. Demekhov for useful discussions.

\section{REFERENCE}

An incomplete list of possible Interplanetary Shocks observed by the PM URL http://umtof.umd.edu/pm/FIGS.HTML (accessed 15 January 2018)

Belyaev P. P., Polyakov S. V., Rapoport V. O., Trakhtengerts, V.Y. Experimental studies of resonance structure in the spectrum of atmospheric electromagnetic background noise in the range of short-period geomagnetic pulsations, Radiophysics and Quantum Electronics. 1989, vol. 32, pp. 491-498.

Bösinger T., Demekhov A.G., Trakhtengerts V.Y. Fine structure in ionospheric Alfven resonator spectra observed at low latitude $(\mathrm{L}=1.3)$. Geophys. Res. Let. 2004, vol. 31. L18802. DOI: $10.1029 / 2004$ GL020777.

Bösinger T., Haldopis C., Belyaev P.P. Yakunin M.N., Semenova N.V., Demekhov A.G., Angelopoulos V. Spectral properties of the ionospheric Alfven resonator as observed at a low latitude station ( $\mathrm{L}=1.3$ ). J. Geophys. Res. 2002. V. 107. N A10. P. 1281. DOI: 10.1029/2001JA005076.

Cully C.M., Ergun R.E., Stevens K., Nammari A., Westfall J. The THEMIS Digital Fields Board. Space Sci. Rev. 2008 , vol. 141 , is. $1-4$, pp. 343-355.
Curto J.J., Araki T., Alberca L.F. Evolution of the concept of sudden storm commencements and their operative identification. Earth, Planets and Space. 2007, vol. 59, no. 11, pp. ixii.

Dovbnya B.V., Guglielmi A.V., Potapov A.S., Kline B.I., On the existence of an over ionospheric Alfven resonator. Solar-Terrestrial Phys. 2013, is. 22, pp. 12-15.

Fedorov E., Schekotov A., Hobara Y., Nakamura R., Yagova N., Hayakawa M. The origin of spectral resonance structures of the ionospheric Alfvén resonator. Single high-altitude reflection or resonant cavity excitation? J. Geophys. Res. 2014, vol. 119, pp. 3117-3129. DOI: 10.1002/2013JA019428.

Gromova L.I., Kleimenova N.G., Levitin A.E., Gromov S.V., Dremukhina L.A., Zelinskyi N.P. Daytime geomagnetic disturbances in high latitudes during a strong magnetic storm on June 21-23, 2015: the initial phase of the storm. Geomagnetizm $i$ aeronomiya [Geomagnetism and Aeronomy]. 2016, vol. 56, no. 3, pp. 302-313. (In Russian).

DOI: $10.7868 /$ S0016794016030056.

Guglielmi A.V. MGD-volny v okolozemnoi plazme [MHD waves in near-Earth plasma]. Moscow, Science Publ. 1979. 140 p. (In Russian).

Hayakawa M., Nickolaenko A.P., Ogava T., Komatsu V. Q-bursts waveforms: model and experiment. Telecommunications and Radio Engineering. 2002, V. 69(19), pp.1735-1750. DOI: 10.1615/TelecomRadEng.v.69.i19.50.

International service on rapid magnetic variations Rapid catalog SSC. URL http://www.obsebre.es/en/rapid (accessed 15 January 2018).

Kangas J., Guglielmi A., Pokhotelov O. Morphology and physics of short-period mfgnetic pulsations (A Review). Space Science Rev. 1998. V. 83, pp. 435-512.

Leonovich A.S., Mazur V.A. Lineinaya teoriya MGDkolebanii magnitosfery. [The linear theory of MHD oscillations of the magnetosphere]. Moscow, Fizmatlit Publ., 2016. 317 p. (In Russian).

Levshin A.A., Frantsuzova V.I, Shkadinskaya G.V. Spectral-temporal analysis of seismic wave. Computer seismology. 1968, vol. 4, p. 197. (In Russian).

Lin R.L., Zhang X.X., Liu S.Q., Wang Y.L., Gong J.C. A three-dimensional asymmetric magnetopause model. $J$. Geo-phys. Res. 2010, vol. 115, A04207, DOI: 10.1029/2009JA014235.

Marmet P. New digital filter for analysis of experimental data. Rev. of Scientific Instruments. 1979, vol. 50, no. 1, pp. 79-83.

Nishida A. 1980. Geomagnitnyi diagnoz magnitosfery [Geomagnetic diagnosis of the magnetosphere]. Moscow, Mir Publ., 299 p. (In Russian).

Nickolaenko A.P., Hayakawa M. Resonances in the Earth Ionosphere cavity. Cluver Academic Publishing. Dordreht, Neederland, 2002, $380 \mathrm{p}$.

Olson J.V., Lee L.G. Pc1 wave generation by sudden impulses. Planet. Space Sci. 1983, V. 31, no.3, pp.295-302.

Parkhomov V. A., Dovbnya B.V., Borodkova N.L., Safargaleyev V.V., Pashinin A.Y. Pulse bursts of geomagnetic pulsations in $0.2-7 \mathrm{~Hz}$ frequency range as a first signal of interaction between interplanetary shock waves and the magnetosphere. Solnechno-zemnaya fizika [Solar-Terrestrial Phys.]. 2014, Is. 25, pp. 21-28. (In Russian).

Parkhomov V.A., Dmitriev A.V., Tsegmed B. On the origin of burst $\mathrm{Pc} 1$ pulsations produced in interaction with an oblique interplanetary shock. Planet. Space Sci. 2015, vol. 109-110, no.1, pp. 21-31.

Parkhomov V.A., Dovbnya B.V., Borodkova N.L., Dmitriev A.V., Safargaleyev V.V., Pashinin A.Y. Impulse Bursts of Geomagnetic Pulsations as the Ground Signature of Contact of Interplanetary Irregularity with the Dayside Mag- 
netopause. Open Access Library J. 2016, 3: e2493. DOI: 10.4236/oalib.1102493

Parkhomov V.A., Borodkova N.L., Yakhnin A.G., Suvorova A.V., Dovbnya B.V., Pashinin A.Y., Kozelov B.V. Global pulse burst of geomagnetic pulsations in $0.2-5 \mathrm{~Hz}$ frequency range as a precursor of sudden commencement of St. Patric geomagnetic storm on 17.03.2015. Kosmicheskie issledovaniya. [Cosmic Res.] 2017, no. 4, pp. 321-334. (In Russian).

Polyakov V.O., Rapoport V.Y. Ionospheric Alfven resonator. Geomagnetizm $i$ aeronomiya [Geomagnetism and Aeronomy]. 1981. vol. 21, no. 5, pp. 610-614. (In Russian).

Safargaleev V., Kangas J., Kozlovsky A.Q., Vasilyev A. ULF noice excited by sudden solar wind dynamic pressure. Annales Geophys. 2002, vol. 20, pp. 1751-1761.

Saito T. Geomagnetic pulsations. Space Sci. Rev. 1969, vol. 10, no. 3, pp. 319-412.

Semenova N.V., Yahnin A.G. Diurnal behaviour of the ionospheric Alfven resonator signatures as observed at high latitude observatory Barentsburg (L=15). Ann. Geophys. 2008, vol. 26, pp. 2245-2251.

Shiokawa K., Nomura R., Sakaguchi K., Otsuka Y., Hamaguchi Y., Satoh M., Katoh Y., Yamamoto Y., Shevtsov B.M., Smirnov S., Poddelsky I., Connors M. The STEL induction magnetometer network for observation of high-frequency geomagnetic pulsations. Earth, Planets and Space. 2010, vol. 62 , pp. 517-524.
Yahnin A.G., Semenova N.V., Ostapenko A.A., Kangas J., Manninen J., Turunen T. Morphology of the spectral resonance structure of the electromagnetic background noise in the range of $0.1-4 \mathrm{~Hz}$ at $\mathrm{L}=5.2$. Annales Geophysicae. 2003, vol. 21, pp. 779-786.

URL: http://umtof.umd.edu/pm/FIGS.HTML (accessed August 16, 2018).

URL: http://www.obsebre.es/en/rapid (accessed August 16, 2018).

URL: https://satdat.ngdc.noaa.gov/sem/goes/data/full (accessed August 16, 2018).

URL: https://cdaweb.sci.gsfc.nasa.gov/cdaweb/istp_public/ (accessed August 16, 2018).

How to cite this article

Parkhomov V.A., Borodkova N.L., Yahnin A.G., Tero Raita, Tsegmed B., Khomutov S.Yu., Pashinin A.Yu., Chilikin V.E., Mochalov A.A. Magnetospheric response of two types in PSc geomagnetic pulsations to interaction with interplanetary shock waves. SolarTerrestrial Physics. 2018. vol. 4, iss. 3, pp. 52-66. DOI: 10.12737/stp43201808. 